\title{
Home Education: \\ Reshaping Teachers and Parents' Responsibilities in the Era of Intensive Parenting
}

\author{
Anna Chinazzi, University of Milano-Bicocca, Italy
}

The European Conference on Education 2021

Official Conference Proceedings

\begin{abstract}
A growing number of parents are choosing not to send their children to school to educate them at home. This is also happening in Italy, where home education has started arousing scholars' interest. We cannot dismiss it as local vogue: it is an international and diverse trend that is likely bound to grow. Moreover, during the last months, the restrictions and the concerns related to the COVID-19 epidemic have been a catalyst for many families worldwide who were already sceptical of the traditional school system and started home educating their children. To better understand this many-sided phenomenon, a look capable of holding its micro-, meso-, and macro-levels is particularly needed. This paper provides an analysis of the homeschooling movement considering the international literature on the topic and an ethnographic study conducted on the parents' point of view in Italy. I will claim that the geo-temporal diffusion of home education bears witness to some characteristics of our contemporary society e.g. the emergence of intensive parenting, the reported loss of social prestige and authority of teachers, and the general narrowing of the epistemic gap between professional and lay visions. Lastly, it calls attention to the tension between mass schooling and the growing demand for more individualised learning paths.
\end{abstract}

Keywords: Home Education, Homeschooling, Contemporary Society, Intensive Parenting

\section{iafor}

The International Academic Forum www.iafor.org 


\section{Introduction}

Homeschooling or elective home education (EHE) is a growing global alternative to conventional education (Cheng \& Donnelly, 2019; Gaither, 2017). This paper explores some of the socio-anthropological reasons for the diffusion of this educational choice in contemporary society, with a focus on the Italian context. The main purpose is to present a theoretical lens to the analysis of home education choice drawing from two main sources: a literature review and an exploratory ethnographic study I conducted in Italy between January 2019 and January 2020 (Chinazzi, 2020).

I will define the topic by highlighting its core characteristics, present the context of the empirical study, illustrate the methodology and finally trace a theoretical analysis.

The central thesis of this contribution is that EHE is not a fringe movement with no connection with the mainstream educational culture, even in some contexts - such as Italywhere it is little practised. I will argue that it is the ultimate expression of some wider trends of contemporary society that have contributed to reshaping parents and teachers' responsibilities. Specifically, I will refer to the intensive parenting ideology and the growing distrust in experts and institutions that is affecting the educational settings.

This analytical perspective supports the relevance of home education as a research topic, not only because it is a fascinating phenomenon itself, but also because - in a broader sense - it challenges modern conceptions of schooling, education, and the family (Kunzman \& Gaither, 2020).

\section{Topic and Context}

During the school closures, which took place in most countries in an effort to limit the spread of COVID-19, a form of home-based distance education was adopted. By taking advantage of the Internet, it helped to mitigate the disruption of children's education. This situation has entailed a reconsideration of home-school partnerships and blurred the boundaries between teachers and parents' roles, demanding an increase of involvement to the latter (Thorell et al., 2020), especially to mothers (Petts, Carlson \& Pepin, 2020).

Nevertheless, this arrangement did not coincide with homeschooling or elective home education in the sense these terms have been usually defined in the scholarly literature in the last decades. Homeschooling or home education is the education of children 'within the home setting, independent of the formal schooling context, and usually overseen by parents' (Hardin \& Farrell, 2003, p.125).

Distance education during the school closures was not, as Gaither (2017) defined homeschooling, 'a deliberately chosen alternative to institutional school' (p. 7), but the pragmatic and temporary use of the home to educate children.

In this paper, we are specifically referring to home education as a parent-led practice that mainly takes place at home, a controversial issue in our contemporary society (Dwyer \& Peters, 2019) that is not universally recognised as a legal option.

In Italy, compulsory education starts at 6 years of age and lasts for 10 years up to 16 years of age. It can be fulfilled by attendance in a school or through home education. In this country, 
home education is a legal and regulated instructional option, formally called Istruzione parentale. It is an uncommon choice since it has just begun to be known by some parents as a viable educational alternative. As a result, it has only recently started arousing Italian scholars' interest (see for example these recent publications: Chinazzi, 2020; Di Motoli, 2019; Giovanelli \& Piromalli, 2021; Leonora, 2019).

Parents who wish to home educate in Italy must annually notify education officials of their decision and self-declare they have the technical and/or economic capacity to home educate their children (legislative decree 297/1994), while children are required to sit a nonstandardised exam at a public school every year (legislative decree 62/2017).

Despite these regulations, it is not possible to determine the actual number of home-schooled students: the annual notification is required to all the families whose children are not enrolled in a public school but could perhaps attend private institutions that are neither scuole statali (State-run schools) nor scuole paritarie (non-State schools recognised by the State as having the same status of State schools).

The data reported in figure 1 show the increasing number of students formally declared in Istruzione parentale in the last four school years. Among those, there is an indeterminable number of home-educated children. Therefore, the graph does not shed light on the quantitative dimension of the specific phenomenon of EHE but bears witness to the growing distrustful attitude towards conventional education. It also shows there has been a steep increase from the last school year with a growth rate of $161 \%$ (while the average growth rate of the previous years was less than 19\%). This boost must be contextualised in the pandemic. For some parents, home education could have been just a temporary solution to tackle the uncertainty they were experiencing; but the COVID-19 epidemic has also worked as a window of opportunity or a catalyst for many families who were already sceptical of the traditional school system and started home educating their children.

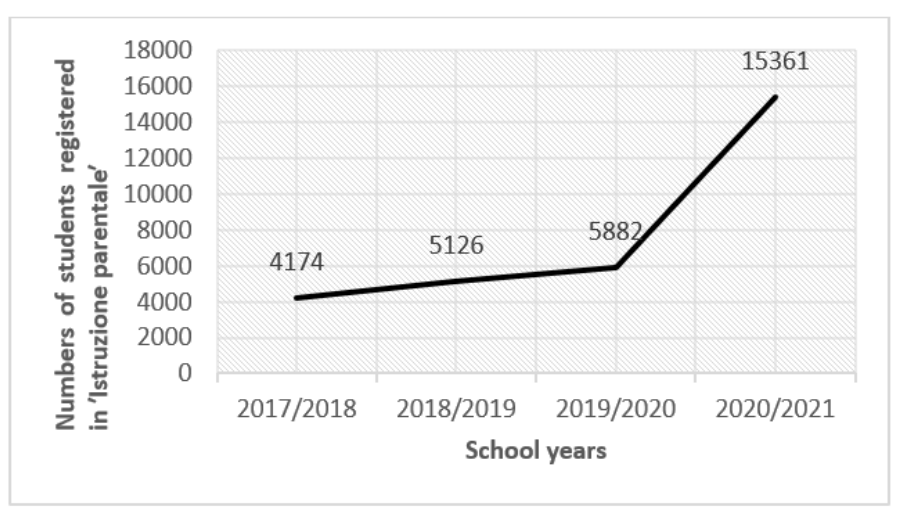

Figure 1: Numbers of Students (6-16 Y.O.) Officially Declared in Istruzione Parentale in Italy in the Last Four School Years. Elaborated from Data Gathered by the Statistical Office of the Ministry of Education, University and Research, Requested by Email by the Author

\section{Methodology}

The following theoretical analysis is based on the literature and insights from the fieldwork.

I have performed a non-systematic hermeneutic literature review (Smythe \& Spence, 2012; Boell \& Cecez-Kecmanovic, 2014; Efron \& Ravid, 2019) on the international literature on 
the phenomenon of EHE. The theoretical discussion will be supported through insights from an ethnography study conducted from January 2019 and 2020 on the parents' point of view in Italy.

An interpretive ethnographic approach was chosen in order to explore in-depth the reasons and the experiences of some families who chose to home educate in a specific context. The strategies used to carry out the study were netnographic observations (Kozinets, 2010) on an Internet community, participant observation at five homeschool gatherings, and ten unstructured interviews with home educators (eight mothers and two fathers). The main purpose of the study was to explore the parental ethnotheories (Harkness \& Super, 1996), i.e., the beliefs of these parents on children, education, and family.

The fieldwork and the literature review provided the author with a glocal perspective, with a privileged viewpoint on a specific context that is conceived as a 'glocality' (Meyrowitz, 2005): unique in many ways but also influenced by global trends.

\section{Common Roots for a Complex Phenomenon}

Homeschooling is an umbrella term since it refers to a variety of approaches, motives, and experiences. As Kunzman (2009) pointed out 'describing the typical homeschool family is not unlike describing the typical public school family - the range of demographics, philosophies and practices make such a generalization practically impossible' (p. 312).

Parents' motivation to home educate has been one of the major issues in the scholarship on this phenomenon (Kunzman \& Gaither, 2020). Empirical research has identified heterogeneous motives. The major motivations in the literature are, according to Gaither's analysis (2017), the following:

religious-grounded motivations, academic-anchored reasons, school environment-focused motivations, and family-based rationales. In Italy, conservative and religious parents tend to prefer the traditional school model (Di Motoli, 2019). In this context, parents are led to the decision to home educate more frequently by concerns about the school environment or academic preparation, the desire to provide tailored instruction, and special educational needs of the children that parents perceived are not being met by the teachers. Most of the motives declared by parents can be traced back to the general dissatisfaction with mainstream schools and the belief that home education is the best educational option for the child and the family.

As a growing area of scholarship has pointed out, not all parents are driven by an actual $a$ priori conviction: some of them are 'second-choicers' (Lois, 2017) or 'accidental home educators' (English, 2021) who perceived home education as 'the only option' (Maxwell et al., 2018), a last resort out of frustration after an experience with conventional schools. Parents of gifted children (Jolly \& Matthews, 2013) or children with educational special needs (Kendall \& Taylor, 2016; Maxwell et al., 2018; Morse \& Bell, 2018) fit more frequently into this category.

In the following sections, the topic will be approached from a big-picture perspective, able to keep these diverse motives together. The aim is to answer the question: how does the phenomenon of elective home education fit in the wider contemporary society? I will claim that, in most cases, home educators are not to be considered as a cultural enclave, but the 
exacerbation of some ongoing trends in the parenting culture and the wider society that have contributed to rethinking parents and teachers' roles and responsibilities.

\section{EHE: The Ideology of Intensive Parenting and the Redefinition of the Expertise}

One of the frameworks employed by scholars to describe homeschooling families is 'intensive parenting' (Aurini \& Davies, 2005; Lois, 2012, 2017; Baker, 2019) that is a frequently reified social construction according to which rearing should be 'child-centered, expert-guided, emotionally absorbing, labor intensive, and financially expensive' (Hays, 1996:8), especially for mothers. It works as a cultural script: in the practice, it may generate different responses according to individual, gender, and cultural differences.

The intensification of parenting is not a universally implemented model but a pervasive standard, influenced by the neoliberal ideology and policies (Crozier 2019). It has spread especially in the Anglophone world and in parts of Europe, but some studies have pointed out that the intensification of parenting is gradually becoming a truly global trend (Faircloth et al., 2013).

Intensive parenting is frequently addressed as 'intensive mothering' (Lois, 2012, 2017; Baker 2019) by the authors who stress it is a gender-specific theory originally developed by Hays (1996). Although a 'new model father' mirroring intensive mothering has been fostered by policymakers and experts, dominant ideologies of motherhood and fatherhood seem to remain very different (Faircloth, 2014). Every analysis based on this conceptual framework must take into account a potential difference in the parents' involvement in heteroparental families, with fathers still reluctant (often unconsciously) to detach from the breadwinner ethics and hence, for instance, less likely to become stay-at-home caregivers than mothers.

This cultural model is fuelled by what has been called 'parental determinism' (Furedi, 2008), i.e., the belief that parents and their parenting are the main determinants of children's development and future success. This causalist reading has led to an expansion of parental responsibility or, as Faircloth (2014) put it, an 'inflation of the parenting role', encouraging greater involvement in children's lives, including their education.

Contemporary home education has been described as the ultimate form of parental involvement in a child's education (Neuman \& Aviram, 2015) and can be neatly seen as an expression of the intensive parenting ideology. Home education often entails a financial effort and, above all, emotional labour to deal with the added stress to the child-rearing 'conventional' practices and the anxiety related to the high self-expectations that the internalisation of intensive parenting produces (Baker 2019; Faircloth \& Murray 2015; Lois, 2012).

The effort to arrange temporally and financially expansive experiences for the children was a recurrent theme I abstracted from the interviews to the participants of the ethnographic study, parents engaged in home education in Italy. One of them, a 39-year-old woman and workingclass single mother, admitted: 'Whether it is right or wrong, I live my life for my kid' ${ }^{1}$. Her proud tone clashed with the diplomatic opening, revealing her awareness that the intensive parenting ideal is not shared by everyone.

\footnotetext{
${ }^{1}$ Interview 16/12/2019.
} 
In this 'new' parenting culture, child-rearing practices are not meant to be improvised but thought, studied, and learned. Furedi (2008) pointed out that in recent years parenting has become a difficult job, marked by constant anxiety. The requirements for parental care have increased, legitimising the influence of professional experts, a phenomenon he called 'professionalization of parenting'. Yet child-rearing advice has become more and more unstable (Lee et al, 2014), encouraging public conflicts and parents' hesitancy.

The diffusion of intensive parenting has consequences in reshaping the boundaries between parents and teachers' roles and responsibilities because intensive parents are more likely to challenge teacher professionalism by intervening in their child's schooling undermining the practitioners (Crozier, 2019). This aspect is exacerbated in the case of EHE since parents decide to take complete responsibility for their children's education.

\section{EHE and the Redefinition of the Expertise}

The challenge of teachers is legitimised by an ongoing cultural shift, i.e., the narrowed social gap between professional and lay visions that also affects the educational field. In the classification of the Global Teacher Status Index of 2018 (Dolton et al., 2018), elaborated by the Varkey Foundation, Italy was the $33^{\text {rd }}$ out of the 35 countries included in the study and the last of the European countries involved.

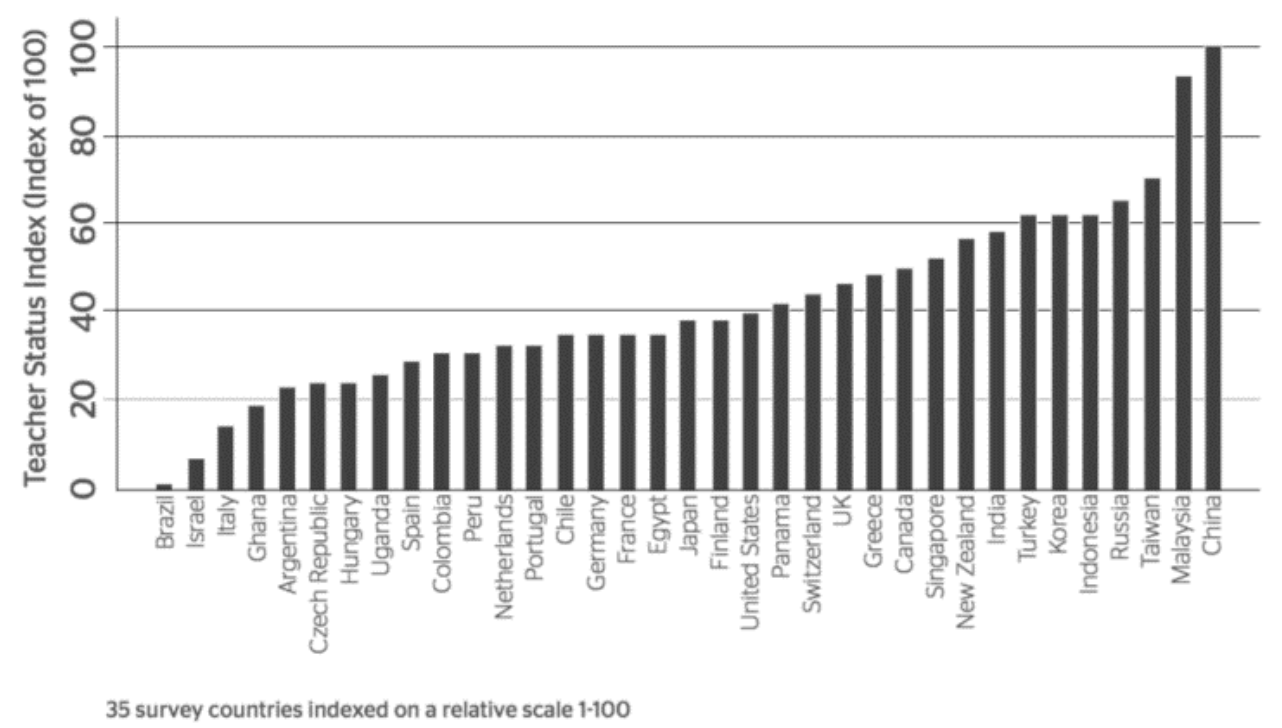

Figure 2: The Varkey Foundation Global Teacher Status Index 2018 (GTSI, 2018).

Dei (2015) warned that the social status of this profession is substantially worse in teachers' perceptions than it is in reality, i.e., in public opinion. Even in this scenario, it is significant to notice that the attitude of some parents has contributed to the diffusion of the cliche that teachers have low social prestige and are deprived of their authority.

This critical attitude towards teachers can be related to renowned sociological readings on contemporary western societies claiming that public trust in experts has declined considerably (Beck et al., 1992). Among the proximate reasons of the recent past for this wane, we can identify the role of the above-mentioned conflicting pluralism of experts and the Internet. 
The Internet search engines and social media have played a pivotal role in the diffusion and decentralisation of knowledge, but some scholars have pointed out that the other side of the coin is the 'flattening of expertise' (Brabazon 2006). With knowledge being accessible, experts can be more easily questioned by everyone.

The hypothesis is that deepening distrust in experts and institutions have led intensive parents to self-select the experts' views to endorse or choose to rely on themselves. The participants of my ethnographic study were generally relucted to identify just a few experts or theories that inspired their child-rearing practices, moving towards a do-it-yourself education. For instance, one of the interlocutors of the study said: 'I am for the multipedagogy' ${ }^{2}$. Likewise, another home educator told me: 'I think everyone is stuck on his own [perspective]. There is only Steiner, only Montessori! We [as parents] take the good from each of them ${ }^{3}$.

The individualisation of the educational practices was extremely important to these parents. In the words of three of my interlocutors: 'Schools don't respect the individual, but the system, the schedule, the deadlines ${ }^{4}$; 'I'm not against school education but [...] teachers didn't see him [my child] as an individual' ${ }^{5}$; '[The school] wasn't suitable for their characteristics - in my opinion. A thing that really affected... // concerned us was the levelling, the unbelievable standardization ${ }^{\prime 6}$. In the ethnographic study emerged that one of the most recurrent motives to home educate was the discrepancy between what the school could offer and the child's particular characteristics.

In this parenting culture, children are seen as unique learners, but conventional instructional strategies are not meant to address the individual learning characteristics, besides the explicit recognition of special educational needs and disabilities for some pupils.

This contemporary educational issue has been tackled by Tomlinson (2014) who provided an operational framework to implement differentiated instruction in the classroom, drawing from different teaching methods to suit the interests, needs and abilities of all learners. Barriers to its application, such as the overload assigned to teachers and time constraints (AlShaboul, Al-Azaizeh \& Al-Dosari 2020), remind us of the wider difficulty to fulfil a project of both personalised and mass education, an unresolved tension that is encouraging many families to withdraw their children from public schools to home educate.

\section{Conclusions}

Parent-led elective home education is a growing educational option in Italy and worldwide. In this contribution, an empirically-informed theoretical approach was adopted to reflect on some aspects of contemporary society that are contributing to the growth of elective home education in some cultural contexts. The analysis presented here is underpinned by the idea that homeschooling families can be observed as magnifying glasses of cultural trends that are embedded in the wider parenting culture and are redefining the role of teachers and parents. Methodologically, a hermeneutic strategy was employed to combine the insights from an ethnographic study on a non-representative sample in Italy with the international literature on the topic. Aware of the limitations of this approach, the analysis does not aim at neutrally

\footnotetext{
${ }^{2}$ Interview 16/09/2019.

${ }^{3}$ Interview 16/12/2019, same interlocutor of note 1 .

${ }^{4}$ Interview 16/12/2019, same interlocutor of notes 1 and 3 .

${ }^{5}$ Interview 10/12/2019.

${ }^{6}$ Interview 16/09/2019, husband of the interlocutor of note 2 . The couple was interviewed simultaneously.
} 
describing a matter of fact but attempts - from a local perspective-to open a critical reflection on this rapidly evolving phenomenon.

The parent-led practice of home education is a 'significant choice' due to its serious implications (Guterman \& Neuman, 2017) whose general premise is found in the desire of parents to directly control the education of their children within the context of the family home (Jolly \& Matthews, 2020). It can be framed as a reaction grounded in the widespread loss of trust in the public educational school system (Leonora, 2019) and a certain conception of childhood and parental involvement (Aurini \& Davies, 2005; Neuman \& Aviram, 2003; Lois, 2017).

In a social landscape marked by a growing scepticism towards mainstream expertise, teachers' professionalism is contested by intensive parents who desire to provide their children with a tailored education. In this contribution, I have argued that the diffusion of the intensive parenting ideology and the growing mistrust in experts and institutions are informing the contemporary parenting cultures. These culture trends may intertwine, (re)shaping homeschool relations. The ultimate expression of this reconfiguration can be found in the case of elective home education.

Moreover, these cultural trends challenge the school system to reaffirm teachers' expertise in new ways and to rethink its role by negotiating between the necessity to guarantee public education to everyone and the demand for more attention to students' individual differences. In this perspective, home educators bear witness to the wider and growing demand for individualised - or even personalised-education that cannot easily be fulfilled in a conventional school context. 


\section{References}

Al-Shaboul Y., Al-Azaizeh M., \& Al-Dosari N. (2020). Differentiated Instruction between Application and Constraints: Teachers' Perspective. European Journal of Educational Research, 10(1), 127-143. Doi: 10.12973/eu-jer.10.1.127

Aurini, J., \& Davies, S. (2005). Choice without markets: Homeschooling in the context of private education. British journal of sociology of education, 26(4), 461-474. Doi: $10.1080 / 01425690500199834$

Baker, E. E. (2019). Motherhood, homeschooling, and mental health. Sociology Compass, 13(9), e12725. Doi: 10.1111/soc4.12725

Beck, U., Lash, S., \& Wynne, B. (1992). Risk society: Towards a new modernity. Sage.

Boell, S. K., \& Cecez-Kecmanovic, D. (2014). A hermeneutic approach for conducting literature reviews and literature searches. Communications of the Association for information Systems, 34(12), 257-286. Doi: 10.17705/1CAIS.03412

Brabazon, T. (2006). The Google Effect: Googling, Blogging, Wikis and the Flattening of Expertise. Libri 56, 157-167. Doi: 10.1515/LIBR.2006.157

Cheng A., \& Donnelly M. (2019). New Frontiers in Research and Practice on Homeschooling. Peabody Journal of Education, 94(3), 259-262. Doi:

10.1080/0161956X.2019.1617576

Chinazzi, A. (2020). Homeschooling and prefigurative culture in Italy. Education Sciences \& Society-Open Access, 11(2). Doi: 10.3280/ess2-2020oa9489

Crozier, G. (2019). Interrogating parent-school practices in a market-based system. The professionalisation of parenting and intensified parental involvement: is this what schools want? In The Wiley Handbook of Family, School, and Community Relationships in Education (pp. 315-332). Wiley-Blackwell.

Dei, M. (2015). An Inquiry into the Social Prestige of Teachers in Italy. Italian Journal of Sociology of Education, 7(3), 244-266. Doi: 10.14658/pupj-ijse-2015-3-11

Di Motoli, P. (2019). Homeschoolers in Italy. Italian Journal of Sociology of Education, 11(2). Doi: 10.14658/pupj-ijse-2019-2-19

Dolton, P., Marcenaro, O., Vries, R. D., \& She, P. W. (2018). Global teacher status index 2018. Retrieved July 26, 2021, from https://www.varkeyfoundation.org/.

Efron, S. E., \& Ravid, R. (2018). Writing the literature review: A Practical Guide. NY: The Guilford Press.

English, R. (Ed.) (2021). The Accidental Home Educator: A New Conceptualisation of Home Education Choice. In English, R. (Ed.). Global Perspectives on Home Education in the 21st Century (pp. 30-48). IGI Global. 
Furedi, F. (2008). Paranoid Parenting. Why Ignoring the Experts May be Best for Your Child. Continuum.

Gaither, M. (Ed.) (2017). The Wiley handbook of home education. John Wiley \& Sons.

Giovanelli G., \& Piromalli L. (2021). Practising "Istruzione Parentale": Becoming a Homeschooling Parent in Italy. In English, R. (Ed.) (2021). Global Perspectives on Home Education in the 21st Century (pp. 159-177). IGI Global.

Guterman, O., \& Neuman, A. (2017). Different reasons for one significant choice: Factors influencing homeschooling choice in Israel. International Review of Education, 63(3), $303-318$.

Harding, T., \& Farrell, A. (2003). Home schooling and legislated education. Australia and New Zealand Journal of Law and Education, 8(1), 125-133.

Harkness, S., Super, C. (1996). Parents' Cultural Belief Systems: Their Origins, Expressions, and Consequences. Guilford Press.

Hays, S. (1996). The Cultural Contradictions of Motherhood. Yale University Press.

Jolly, J. L., \& Matthews, M. S. (2020). The shifting landscape of the homeschooling continuum. Educational Review, 72(3), 269-280. Doi:

$10.1080 / 00131911.2018 .1552661$

Jolly, J. L., Matthews, M. S., \& Nester, J. (2013). Homeschooling the gifted: A parent's perspective. Gifted Child Quarterly, 57(2), 121-134. Doi: $10.1177 / 0016986212469999$

Kendall, L., \& Taylor, E. (2016) 'We can't make him fit into the system': parental reflections on the reasons why home education is the only option for their child who has special educational needs. Education 3-13, 44:3, 297-310, Doi: 10.1080/03004279.2014.974647

Kozinets, R. V. (2010). Netnography: Doing ethnographic research online. Sage publications.

Kunzman, R. (2009). Understanding homeschooling: A better approach to regulation. Theory and research in Education, 7(3), 311-330. Doi: 10.1177/1477878509343740

Kunzman, R., \& Gaither, M. (2020). Homeschooling: An updated comprehensive survey of the research. Other Education, 9(1), 253-336.

Lee, E., Bristow, J., Faircloth, C., \& Macvarish, J. (2014). Parenting culture studies. Springer.

Leonora, A. M. (2019). Veder crescere un albero. La prospettiva capovolta dei processi educativi non standard in Italia. Annali della facoltà di Scienze della formazione Università degli studi di Catania, 18, pp. 67-79. Doi: 10.15169/unict-asdf.18.2019.5

Lois, J. (2012). Home is where the school is. New York University Press. 
Lois, J. (2017). Homeschooling motherhood. In Gaither, M. (Ed.) (2017). The Wiley handbook of home education (pp.186-206). John Wiley \& Sons.

Maxwell, N., Doughty, J., Slater, T., Forrester, D., \& Rhodes, K. (2020). Home education for children with additional learning needs-a better choice or the only option?.

Educational Review, 72(4), 427-442. Doi: 10.1080/00131911.2018.1532955

Meyrowitz, J. (2005). The rise of glocality: New senses of place and identity in the global village. In K. Nyíri (Ed.), A sense of place: The global and the local in mobile communication (pp. 21-30). Vienna: Passagen.

Morse, M. L., \& Bell, S. M. (2018). Homeschooling: A growing school choice option for meeting special educational needs. International Journal of Educational Reform, 27(2), 156-172. Doi: 10.1177/105678791802700203

Neuman, A., \& Aviram, A. (2003). Homeschooling as a fundamental change in lifestyle. Evaluation \& Research in Education, 17(2-3), 132-143. Doi: 10.1080/09500790308668297

Petts R.J., Carlson D.L., \& Pepin J.R. (2020), A gendered pandemic: Childcare, homeschooling, and parents' employment during COVID-19. Gender Work Organ. 28(S2), 515-534. Doi: 10.1111/gwao.12614

Smythe, E., \& Spence, D. (2012). Re-viewing literature in hermeneutic research. International Journal of Qualitative Methods, 11(1), 12-25. Doi:

$10.1177 / 160940691201100102$

Thorell, L. B., Skoglund, C., de la Peña, A. G., Baeyens, D., Fuermaier, A. B. M., Groom, M. J., Mammarella, I. C., van der Oord, S., van den Hoofdakker, B. J., Luman, M., de Miranda, D. M., Siu, A. F. Y., Steinmayr, R., Idrees, I., Soares, L. S., Sörlin, M., Luque, J. L., Moscardino, U. M., Roch, M., ... Christiansen, H. (2021). Parental experiences of homeschooling during the COVID-19 pandemic: Differences between seven European countries and between children with and without mental health conditions. European Child \& Adolescent Psychiatry. Doi: 10.1007/s00787-02001706-1

Tomlinson, C. A. (2014). The differentiated classroom: Responding to the needs of all learners. Ascd. 